\title{
6 OPEN ACCESS \\ Predictive value of the amplitude integrated EEG in infants with hypoxic ischaemic encephalopathy: data from a randomised trial of therapeutic hypothermia
}

\author{
Denis Azzopardi, on behalf of the TOBY study group
}

\begin{abstract}
Correspondence to
Professor Denis Azzopardi, Department of Paediatrics, 5th Floor Hammersmith House, Hammersmith Hospital, DuCane Road, London W120NN, UK; d.azzopardi@imperial.ac.uk
\end{abstract}

Received 18 January 2013 Revised 1 May 2013 Accepted 11 May 2013 Published Online First 25 June 2013

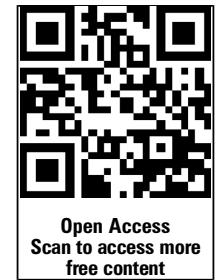

To cite: Azzopardi D, on behalf of the TOBY study group. Arch Dis Child Fetal Neonatal Ed 2014:99: F80-F82.

\begin{abstract}
The amplitude integrated $\mathrm{EEG}(\mathrm{aEEG})$ is reputed to be one of the best predictors of neurological outcome following hypoxic ischaemic encephalopathy in term newborns and was used to select infants into trials of neuroprotection with hypothermia, but its predictive value and the effect of moderate hypothermia on the aEEG have not previously been examined in a randomised study. The positive predictive value (PPV) of the aEEG recorded within $6 \mathrm{~h}$ of birth for death or disability at 18 months of age was determined in 314 infants born after 35 weeks gestation who were randomised to receive standard care with or without cooling for $72 \mathrm{~h}$. The aEEG was classified according to voltage and by pattern. The PPV of a severely abnormal aEEG assessed by the voltage and pattern methods was 0.63 and 0.59 respectively in non-cooled infants and 0.55 and 0.51 in cooled infants ( $p>0.05$ ). Although the differences in PPV between cooled and non-cooled groups were not significant, they are consistent with observational studies showing a lower PPV in infants treated with hypothermia, probably due to a neuroprotective effect of cooling.
\end{abstract}

\section{INTRODUCTION}

Early prediction of outcome following hypoxic ischaemic encephalopathy (HIE) is important for counselling parents of affected infants. The positive predictive value (PPV) of the amplitude integrated EEG (aEEG) for adverse outcome following HIE is the proportion of infants with an abnormal aEEG who have an adverse outcome. The aEEG is reputed to be one of the best predictors of neurological outcome following HIE in term newborns and was used to select infants into trials of neuroprotection with hypothermia. ${ }^{1-3}$ Previous reports have suggested that the PPV of the aEEG obtained within $6 \mathrm{~h}$ of birth is $>80 \%$ in infants with HIE and that moderate hypothermia may alter the predictive value, but these were observational, nonrandomised studies that included historical controls and subgroups from randomised studies and so selection bias could have occurred. ${ }^{4}$ Since moderate hypothermia reduces the rates of death or disability at 18 months in infants with moderate or severe HIE it is possible that the PPV of the aEEG may differ in cooled compared with non-cooled infants. ${ }^{3}$ The aEEG was one of the main entry criteria in the TOBY randomised trial of hypothermia for perinatal asphyxial encephalopathy and this

\section{What is already known on this topic}

The amplitude integrated $\mathrm{EEG}(\mathrm{aEEG})$ is one of the best predictors of neurological outcome following hypoxic ischaemic encephalopathy.

- Treatment with cooling increases the rates of survival with a normal neurological outcome and may alter the predictive value of early predictors including the aEEG.

\section{What this study adds}

The predictive value for adverse outcome at 18 months of age of the aEEG recorded within $6 \mathrm{~h}$ of birth in neonates with hypoxic ischaemic encephalopathy is lower than previously reported.

- Consistent with observational studies the predictive value is reduced in infants treated with cooling compared with non-cooled infants.

afforded an opportunity to determine the influence of moderate hypothermia on the PPV of the aEEG.

\section{METHODS}

A single expert assessor (DA) masked to treatment allocation and outcome examined the aEEG records of infants born at or after 36 weeks gestation suffering from moderate or severe HIE, who were participants in the TOBY randomised trial of standard care or standard care plus cooling to $33.5^{\circ}$ $\mathrm{C}$ for $72 \mathrm{~h}^{2}{ }^{2}$ The inclusion criteria of the TOBY trial required the presence of an abnormal aEEG as well as clinical criteria of HIE. The aEEG was recorded for at least $30 \mathrm{~min}$ within $6 \mathrm{~h}$ of birth prior to randomisation and before initiation of cooling. Although the aEEG was usually recorded for several hours, only the prerandomisation record was available for analysis for this study. The details of the TOBY trial have been published. ${ }^{2}$

The aEEG background activity was classified according to published voltage criteria and by background pattern. ${ }^{5}$ aEEG records with severely suppressed voltage or with burst suppression, continuous low voltage or flat trace patterns were classed as severely abnormal. The PPVs with 95\% 
CIs for an adverse outcome consisting of death or severe disability at 18 months of age were calculated. Severe disability was defined the same as in the TOBY trial as any of: cerebral palsy with a Gross Motor Function Score of 3-5 (on a scale of 1-5); a Mental Developmental Index of the Bayley Infant Developmental Scales of less than 70 (more than 2 SDs below the mean); and bilateral cortical visual impairment. ${ }^{2}$

The two sample test for significance of proportions was used to test for differences in the PPVs in cooled and non-cooled groups. A two sided $\mathrm{p}$ value $<0.05$ was considered significant.

The TOBY protocol was approved by the London Multicenter Research Ethics Committee and the local research ethics committee of each participating hospital. Conduct of the study was overseen by an independent trial steering committee with advice from an independent data monitoring and ethics committee.

\section{RESULTS}

aEEG records of an adequate quality were available for 314 of the 325 participants of the TOBY trial. The gestational age of the study infants was median (IQR) 40 (39-41) weeks, Apgar score at $5 \mathrm{~min}, 3(1-5)$, first arterial/capillary blood $\mathrm{pH}, 6.90$ (6.78-7.01) and base deficit, 18.25 (23.27-13.03), and the age at randomisation was $4.68(3.7-5.48)$ hours, similar to those of the entire TOBY trial group. Of the 314 infants, 158 received standard care with cooling and 156 standard care only. In all, 67 of the 158 infants treated with cooling and 84 of the 156 infants who received standard care only died or were severely disabled at 18 months of age $(p=0.04)$.

The PPV of an abnormal aEEG for adverse outcome at 18 months is shown in table 1.

The PPV of the aEEG was lower in the infants treated with cooling than in the non-cooled infants but the difference was not statistically significant. A severely abnormal aEEG had a slightly higher PPV for an adverse outcome when assessed by the voltage rather than the pattern method. For the pattern classification method, the highest PPV was achieved by combining the continuous low voltage and flat trace patterns (table 1 and figure 1).
A total of $17 / 314$ infants were considered to have normal background aEEG or mild abnormalities only such as absence of sleep wake cycling with normal voltage or a slight discontinuity, but electrical seizures were identified in seven of these infants. Of the 17 infants with normal or mildly abnormal background aEEG, 3/7 with electrical seizures and 4/10 without electrical seizures had an adverse outcome at 18 months. Another 5/314 infants were considered to have continuous seizure activity on the aEEG and four of these five infants had an adverse outcome at 18 months.

\section{DISCUSSION}

Previous studies suggested that the PPV for adverse outcome of an abnormal aEEG obtained within $6 \mathrm{~h}$ of birth in infants with HIE is very high, greater than $80 \%$, but is lower following moderate hypothermia. It is notable that the PPV for adverse outcome in this randomised study is lower than previously reported from observational studies carried out in the precooling era and from the study from one centre that included subjects in cooling trials. ${ }^{4}$ Although the TOBY study was a large multicentre international trial, this finding is unlikely to be due to the quality of the recordings as only good quality aEEG records were analysed and the assessor was masked to the clinical outcomes of the infants. The timing of recording also does not explain the low predictive value noted in this study since almost all previous studies reported data from 3 to $6 \mathrm{~h}$ of age, as in this study. It is possible that the indication for performing the aEEG or for transfer to specialist centres that carried out aEEG differed in previous studies, but this is impossible to ascertain.

Although most previous studies reported a very high PPV of the aEEG recorded within $6 \mathrm{~h}$ of birth, our data are in accord with those of a prospective non-randomised study of 108 infants that met entry criteria for cooling. ${ }^{6}$ In that study, the PPV of the aEEG in normothermic infants was 0.62 and was 0.51 in cooled infants, which is very similar to this study. The rates of adverse outcome in non-cooled infants in the randomised trials of cooling in infants with moderate or severe HIE

Table 1 Positive predictive value (PPV) of the amplitude integrated EEG (aEEG) in infants with hypoxic ischaemic encephalopathy randomised to treatment with or without cooling

\begin{tabular}{|c|c|c|c|c|c|c|c|}
\hline & DDIS (N) & Not DDIS (N) & Total (N) & PPV & $95 \%-$ & $95 \%+$ & p Value \\
\hline \multicolumn{8}{|l|}{ aEEG voltage } \\
\hline \multicolumn{8}{|c|}{ Moderate suppression } \\
\hline Cooled & 13 & 43 & 56 & 0.23 & 0.12 & 0.34 & 0.06 \\
\hline Not cooled & 24 & 37 & 61 & 0.39 & 0.27 & 0.52 & \\
\hline \multicolumn{8}{|c|}{ Severe suppression } \\
\hline Cooled & 50 & 41 & 91 & 0.55 & 0.45 & 0.65 & 0.27 \\
\hline Not cooled & 53 & 31 & 84 & 0.63 & 0.53 & 0.73 & \\
\hline \multicolumn{8}{|l|}{ aEEG pattern } \\
\hline \multicolumn{8}{|l|}{ DNV } \\
\hline Cooled & 2 & 26 & 28 & 0.07 & 0 & 0.17 & 0.07 \\
\hline Not cooled & 6 & 18 & 24 & 0.25 & 0.08 & 0.42 & \\
\hline \multicolumn{8}{|l|}{ BS/CLV/FT } \\
\hline Cooled & 61 & 58 & 119 & 0.51 & 0.42 & 0.6 & 0.25 \\
\hline Not cooled & 71 & 50 & 121 & 0.59 & 0.5 & 0.67 & \\
\hline \multicolumn{8}{|l|}{ CLV/FT } \\
\hline Cooled & 35 & 24 & 59 & 0.59 & 0.47 & 0.71 & 0.17 \\
\hline Not cooled & 42 & 17 & 59 & 0.71 & 0.59 & 0.81 & \\
\hline
\end{tabular}


Figure 1 Positive predictive value (PPV) of two methods for classifying amplitude integrated $\mathrm{EEG}(\mathrm{aEEG})$ as severely abnormal according to combination of pattern of the aEEG. The $X$ axis is the $a E E G$ grade classified by pattern. BS, burst suppression; CLV, continuous low voltage; FT, flat trace.

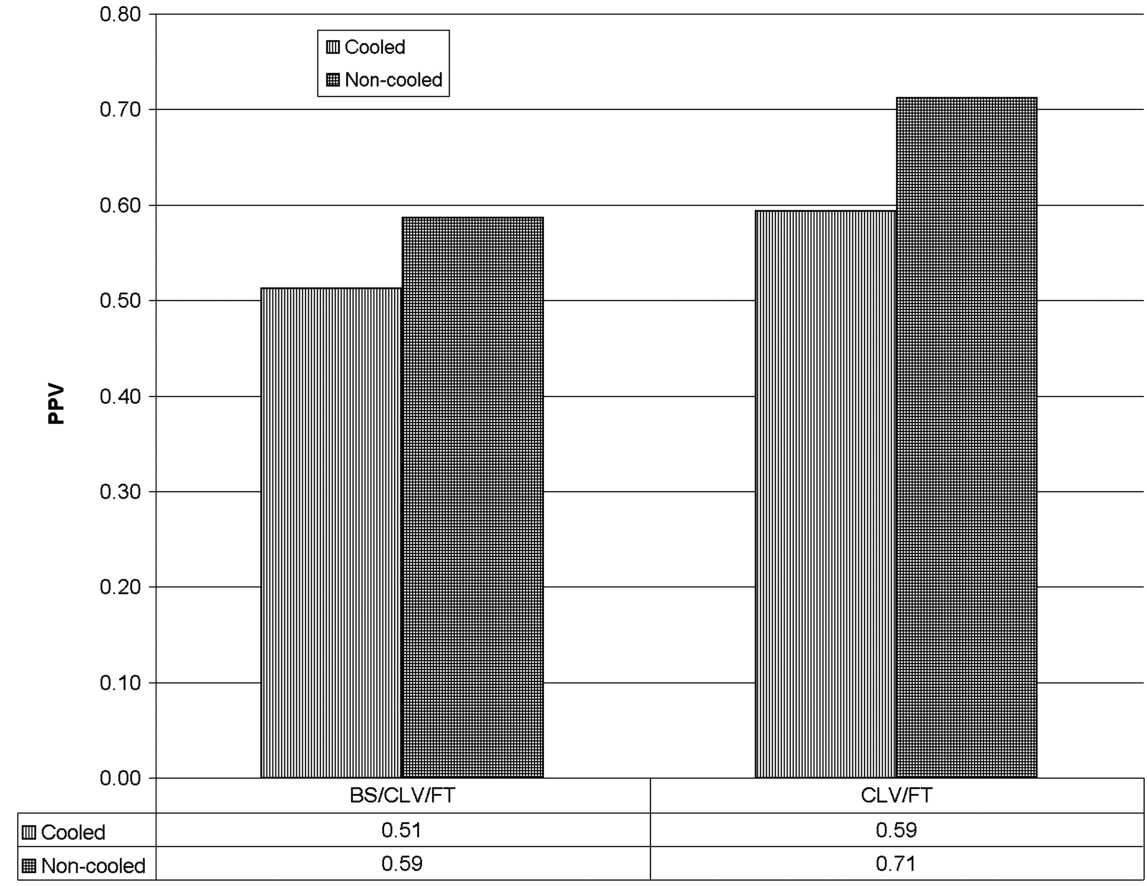

was approximately $60 \%$ and fell to $45 \%$ in the cooled infants, ${ }^{3}$ which are similar to the PPVs observed in this study. Since the aEEG correlates well with the severity of HIE, this suggests that the PPV of the aEEG recorded within $6 \mathrm{~h}$ of birth in infants with HIE in most previous reports was excessively high.

The predictive value for adverse outcome at 18 months of age of the aEEG recorded within $6 \mathrm{~h}$ of birth was modestly reduced in infants treated with cooling compared with non-cooled infants but the reduction was not statistically significant. These data are in accord with two non-randomised studies that examined the PPV of the aEEG in normothermic and cooled infants. $^{4} 6$ The modest reduction in the PPV for adverse outcome in cooled infants compared with non-cooled infants is best explained by the beneficial effect of cooling on neurological outcomes following HIE. The magnitude of the reduction in the predictive value of the aEEG with cooling found in this study is not dissimilar to the effect of cooling on neurological outcomes (risk difference for adverse outcome between cooled and noncooled infants was $-0.11,95 \% \mathrm{CI}-0.18$ to -0.04$).^{3}$

The predictive values of the aEEG assessed by the voltage criteria and by pattern were similar, as has been generally noted in previous studies. Since modern aEEG systems also display the raw EEG, the pattern method may be preferable as it is similar to standard EEG classification. However, inexperienced users may find the voltage method simpler to use. Previous studies have combined the burst suppression, low voltage and flat traces to define an abnormal pattern, but in this study the best PPV was obtained by combining the low voltage and flat trace patterns and excluding the burst suppression pattern. However, as in other studies using aEEG as an entry criterion, the sensitivity and specificity of the aEEG, which are key indicators of the prognostic performance of a test, could not be assessed, as entry into the TOBY study required the presence of an abnormal aEEG.

A lower PPV of the aEEG in cooled compared with noncooled infants was observed in infants with moderate as well as in those with severe suppression of the aEEG, suggesting that cooling has a beneficial effect in infants with a wide spectrum of severity of encephalopathy. The predictive values from this study may be a helpful guide when counselling parents about the need for therapeutic hypothermia and the likely outcome of affected infants.

Collaborators The TOBY study group. ${ }^{2}$

Contributors The author conceived the study, analysed the data and wrote this report. The collaborators were members of the TOBY study group who instigated, managed and carried out the TOBY neuroprotection trial which provided the data for this report.

Funding The TOBY randomised trial of moderate hypothermia to treat perinatal asphyxial encephalopathy was supported by the Medical Research Council (UK).

Competing interests None.

Ethics approval London Multicenter Research Ethics Committee and the local research ethics committee of each participating hospital.

Provenance and peer review Not commissioned; externally peer reviewed.

Data sharing statement All data from the TOBY trial have been published and are open access.

Open Access This is an Open Access article distributed in accordance with the Creative Commons Attribution Non Commercial (CC BY-NC 3.0) license, which permits others to distribute, remix, adapt, build upon this work non-commercially, and license their derivative works on different terms, provided the original work is properly cited and the use is non-commercial. See: http://creativecommons.org/ licenses/by-nc/3.0/

\section{REFERENCES}

1 van Laerhoven $\mathrm{H}$, deHaan TR, Offringa $M$, et al. Prognostic tests in term neonates with hypoxic-ischemic encephalopathy. Pediatrics 2013;131:88-98.

2 Azzopardi DV, Strohm B, Edwards AD, et al. Moderate hypothermia to treat Perinatal asphyxial encephalopathy. N Engl J Med 2009;361:1349-58.

3 Edwards AD, Brocklehurst P, Gunn AJ, et al. Neurological outcomes at 18 months of age after moderate hypothermia for perinatal hypoxic ischaemic encephalopathy: synthesis and meta-analysis of trial data. BMJ 2010;340:c363.

4 Thoresen $M$, Hellström-Westas L, Liu X, et al. Effect of hypothermia on amplitudeintegrated electroencephalogram in infants with asphyxia. Pediatrics 2010;126:e131-9.

5 deVries LF, Toet MC. How to assess the aEEG background. J Pediatr 2009;154:625-6.

6 Shankaran S, Pappas A, McDonald SA, et al. Predictive value of an early amplitude integrated electroencephalogram and neurologic examination. Pediatrics 2011;128: e112-20. 